\title{
Application of HEC-RAS (2D) for Flood Hazard Maps Generation for Yesil (Ishim) River in Kazakhstan
}

\author{
Nurlan Ongdas, Farida Akiyanova *, Yergali Karakulov, Altynay Muratbayeva and \\ Nurlybek Zinabdin \\ International Science Complex Astana, Nur-Sultan 010000, Kazakhstan; ongdasn@tcd.ie (N.O.); \\ ergali_1992@mail.ru (Y.K.); altynay_sh@mail.ru (A.M.); nzgeo@mail.ru (N.Z.) \\ * Correspondence: akiyanovaf@mail.ru
}

Received: 27 August 2020; Accepted: 22 September 2020; Published: 24 September 2020

check for updates

\begin{abstract}
The use of hydraulic models for carrying out flood simulations is a common practice globally. The current study used HEC-RAS (2D) in order to simulate different flood scenarios on the River Yesil (Ishim). Comparison of different mesh sizes (25, 50 and $75 \mathrm{~m}$ ) indicated no significant difference in model performance. However, a significant difference was observed in simulation time. In addition, the inclusion of breaklines showed that there was a slight improvement in model performance and a shortening of the simulation time. Sensitivity analysis and the consequent manual calibration of sensitive parameters resulted in a slight improvement (an increase in the model accuracy from $58.4 \%$ for uncalibrated to $59.7 \%$ for calibrated). Following the simulations inundation maps for 10-, 20- and 100-year flood events were obtained. Hazard classification of the flood extents generated indicated that the settlements of Zhibek Zholy and Arnasay were flooded in all the simulated events. Volgodonovka village experienced flooding when a 100-year flood event was simulated. On the other hand, settlement No. 42 did not experience any flooding in any of the scenarios. The model results also demonstrate that the Counter-Regulator was not overtopped in the event of the 100-year hydrograph.
\end{abstract}

Keywords: hydraulic modelling; flood inundation; HEC-RAS 2D; flood hazard; Yesil River

\section{Introduction}

Flooding is a common natural disaster with a devastating and widespread effect responsible for economic losses and mortality [1,2]. This natural hazard is reported to comprise a significant proportion of the total number of reported natural disasters around the globe [1]. It is a problem not only for developing countries, but also for developed countries. It has been estimated that in the period 2002-2016 there were around 300 flood events of different kinds in the Republic of Kazakhstan; $70 \%$ of these events were caused by spring snowmelt [3]. Considering the influence of climate change on the hydrological cycle (especially on the pattern and intensity of precipitation), the occurrence and severity of these events might increase in the future [4-6]. According to Mihu-Pintilie et al. and Lea et al. [2,5], the occurrence of climate-related disasters has seriously risen in a number of regions of the world due to the influence of abrupt changes on hydro-climatic conditions and other disturbances. Another potential factor influencing the occurrence of flood events is land-use change and the development of socio-economic activities in flood prone areas [2,7]. Such actions influence the natural behavior of a river's hydrology and floodplains' response to a flood hazard.

Due to the complex nature of these drivers, they are not completely preventable. However, it is possible to reduce the related risks if adequate flood risk management strategies with information about the flood prone areas is available beforehand $[4,6]$. The understanding, assessment and prediction of floods and their influence have been a necessity for a long time. With recent advancements in computing power as well as technology, this has become more accessible. A good example is the application of 
parallel computing and cloud-computing services in order to meet the high computational demand $[1,6]$. In addition, Geographical Information Systems (GIS) coupled with Remote Sensing (RS) data have significantly facilitated the generation of flood hazard mapping. Remote sensing not only provides input data for model construction, but also provides data for model validation [8]. The combination of climate, hydrological and hydrodynamic models has extended the primary purpose from simple inundation-area identification towards the formulation of climate adaptation and risk-mitigation strategies [1]. However, the complex nature of flooding events as well as the uncertainties related to modelling result in significant challenges for accurate and rapid flood modelling at high resolutions [1].

In general, the concept of flood risk management describes a system, where flood forecasting and flood warning systems play a key role. Flood hazard assessment, through inundation mapping and identification of flood risk zones, is the core element for formulating any flood management strategy $[2,4,6]$. Flood inundation modelling serves an important role of obtaining spatial distribution information on inundation patterns (such as water depth and flow velocity) [9]. This could inform inform on the severity of the hazard, any threats to public safety and potential financial losses [9]. Further, they could be used to support emergency management actions and mitigation policies for future flooding events $[10,11]$. They are also critical for informing the public and policy makers and to receiving support for the formation of suitable governance [11].

The primary tools for performing inundation mapping are hydraulic/hydrodynamic models. They are mostly used for the simulation of flood events, estimation of vulnerable areas, flood management planning and the determination of spatially distributed variables of interest [2]. In general, they describe the fluid motion and the dynamics of the flood wave by solving mathematical equations, which are based on the principles of the conservation of mass and momentum [12]. Depending on the study area as well as the purpose of the project, the user can choose between models with different dimensionalities (1D, 2D, etc.), numerical schemes (finite volume, finite difference, etc.), mesh representations (structured, unstructured, etc.) and equations (Kinematic Wave, Diffusion Wave, Muskingum, etc.). Mihu-Pintilie et al., Patel et al. and Shustikova et al. [2,4,6] have stated that 1D modeling represents the channel processes accurately, but for the assessment of flood wave dynamics in the floodplain, when the capacity of the channel has been exceeded and the flow is spread across a large area in the downstream terrain, 2D would be a better choice. Morsy et al. [13] recommend using fully 2D models with a high degree of detail on the terrain for the purpose of avoiding the uncertainties and limitations, which can arise from the incorrect interpretation of flood dynamics and the inaccurate representation of the relief. According to Teng et al. and Dasallas et al. [1,5], 2D models are mostly used for flood extent mapping and flood risk estimation, as they provide more detailed and reliable results in complex flow simulations. 2D models that solve full shallow water equations are reported to have the capacity to simulate the timing and duration of inundation with high accuracy, though they are data-intensive and have a high computational demand [5,14]. These disadvantages restrict their use for real-time flood forecasting [5]. In the same study, it was reported that they are not viable for areas larger than $1000 \mathrm{~km}^{2}$, if a resolution of less than $10 \mathrm{~m}$ and/or multiple model runs are required.

This study utilized the 2D capacity of HEC-RAS, which has, according to the literature review, a wide range of applications and deploys different schematization complexities [6]. For example, by coupling HEC-HMS and HEC-RAS Thakur et al. [11] generated a system, which can generate flood inundation maps for a given precipitation event. Loi et al. [15] were able to couple SWAT and HEC-RAS for real-time flood forecasting for the Vu Gia-Thu Bon river basin. The model results were adequate, the magnitude and timing of peak flows were accurately predicted for individual storm events. Mihu-Pintilie et al. [2] applied HEC-RAS 2D modelling with LiDAR data to an urban location in order to generate improved flood hazard maps. According to the authors, their results demonstrated sufficiently accurate information regarding vulnerability to flood hazard. Quiroga et al. [16] evaluated HEC-RAS 2D for the generation of flood depth, duration and velocity maps in the case of the Mamore river flood. In the study performed by Vozinaki et al. [17], it was found that $1 \mathrm{~m}$ DEM shows better results than the $5 \mathrm{~m}$ DEM, when 1D HEC-RAS and combined 1D/2D HEC-RAS is used. 
Using coupled 1D/2D HEC-RAS, Patel et al. [4] simulated the flooding event caused by high release from the Ukai Dam and obtained acceptable results. Shustikova et al. [6] performed 2D modelling of a floodplain inundation event in Italy with HEC-RAS and LISFLOOD-FP using the same topographical input data and found that the latter performed slightly better than the former. Another important point was that the computation time required by LISFLOOD-FP is significantly smaller than that of HEC-RAS for the same grid and time step chosen. The findings suggested that the specific relief of the study area can result in ambiguities for large scale modelling, at the same time providing plausible results in terms of the overall model performance. Salt [18] compared the applicability of HEC-RAS (2D) and DSS-WISE for Rancho Cielito Dam Breach modelling. The results indicated that both models provided similar results and the differing numerical schemes of each model did not have a significant influence on the generated inundation boundaries. However, a significantly faster simulation of DSS-WISE was opposed to the capacity of HEC-RAS for terrain modification, which might be necessary at certain areas for which terrain data did not capture important features. Brunner [19] evaluated the 2D capacity of HEC-RAS using the benchmark tests developed by the UK's Joint Defra Environment Agency. The results demonstrated that HEC-RAS performs extremely well compared to other models (TUFLOW, MIKE FLOOD, SOBEK, etc.) that have been tested. Both equations of HEC-RAS (Full Momentum and Diffusion Wave) showed similar results for certain scenarios to which they were applied. Dasallas et al. [5] performed a coupled 1D-2D simulation of the Baeksan Flooding event using HEC-RAS. The results obtained on flood inundation were similar to those obtained by other flood models (Gerris, FLUMEN) and observed data. The authors also claim that HEC-RAS simulated the flooded area more realistically in terms of the ideal behavior of flood dynamics. Rangari et al. [20] assessed the possibility of HEC-RAS use for urban flood simulation for a part of Hyderabad. Using the simulation results, risk maps were developed for different rainfall scenarios. Whereas Kumar et al. [21] applied HEC-RAS and Global Flood Monitoring System for flood extent mapping. The authors have reported that the results obtained and observations were in close agreement. Costabile et al. [22] analyzed the capacity of HEC-RAS for performing rainfall-runoff simulations at the basin scale for the tributary of the River Po. In comparison to the Diffusion Wave equation, the Full Momentum equation has shown very similar results with respect to the 2-D fully dynamic model (SWE-FVM) developed by the authors. HEC-RAS has demonstrated mostly overestimation of SWE-FVM derived flooded areas, the variations in flood areas were observed to increase as the mesh size increases and the return period decreases. In the study by Pilotti et al. [23], hypothetical dam break analysis using Telemac 2D and HEC-RAS 2D was performed. The findings demonstrate that both models reproduce well the experimental hydrograph in terms of shape, peak discharge and flood wave arrival time. In addition, both hydraulic models resulted in a very similar flood extent. Even though hydraulic modelling has demonstrated reliable results, proven its usefulness and is a common practice around the world, there are no published records of its application in the Republic of Kazakhstan for the simulation of floods. There are several potential reasons for this, such as the absence of high-resolution terrain data, river bathymetry data and the lack of high-resolution data for calibration as well as validation. At the same time, flooding due to snowmelt is common in several regions of Kazakhstan (such as Akmola, Karaganda, North Kazakhstan and Kostanay). It has been estimated that 1051 settlements in Kazakhstan are potentially subject to flooding, though there have not been any flood risk assessment studies. In addition to the natural causes (such as rapid snowmelt and river ice-jams) of flood events, construction of houses in the water protection zones have been reported as a cause [24]. The government expenditure for flood prevention and elimination of flood events' consequences for the years 2015, 2016 and 2017 constituted 134.4, 61.97 and 34.6 million USD, respectively. In the Akmola region alone, where our study area is located, the economic losses from floods in 2015 comprised around 49 million USD. Regarding the influence of climate change on the occurrence of flooding events in Kazakhstan, the study by CAREC [25] reported that for the River Zhabay, for example, spring floods may become more common and intense, if not routine in the future. Hydraulic modelling could have also been useful for dealing with the recent event in Uzbekistan. 
On 1 May 2020, the Sardoba dam collapsed, resulting in the displacement of thousands of people and serious economic losses to Kazakhstan and Uzbekistan. Conduction of probabilistic dam break analysis studies beforehand using hydraulic modelling could have helped for the evacuation actions as well as for the consideration of protection measures. All of these highlight the areas which could potentially benefit from the use of hydrodynamic modelling. The current study as a pilot project is therefore concerned with the application of the hydrodynamic model HEC-RAS for the purpose of identifying the inundation areas during flooding events of different return periods.

\section{Materials and Methods}

\subsection{Study Area}

The study site covers the territory between the Astana Reservoir (in the east) and the Counter-Regulator (in the west). The reservoir is located $50 \mathrm{~km}$ away from the capital city of the Republic of Kazakhstan, Nur-Sultan, in the eastern direction; while the Counter-Regulator is located within the city limits. Both structures are in principle earth embankment dams. Figure 1 demonstrates the study area and the location of these two hydraulic structures. The Astana Reservoir has the primary function of supplying Nur-Sultan with drinking water. The Counter-Regulator's main function is to hold excess water from the reservoir during the spring snowmelt in order to prevent flooding of Nur-Sultan. The reservoir was built in 1970 and the regulator in 2011. There are four settlements (Zhibek Zholy, Arnasay, Settlement No. 42 and Volgodonovka) in the study area, with a total population of around 8528 people [24]. Among the four, Zhibek-Zholy is periodically subject to spring floods. The climate of this area is described as continental, with a total annual precipitation of between $200-400 \mathrm{~mm}$ and a temperature range of $-40{ }^{\circ} \mathrm{C}$ to $+35^{\circ} \mathrm{C}$ [25]. Approximately $25-30 \%$ of the total precipitation falls in the cold season.

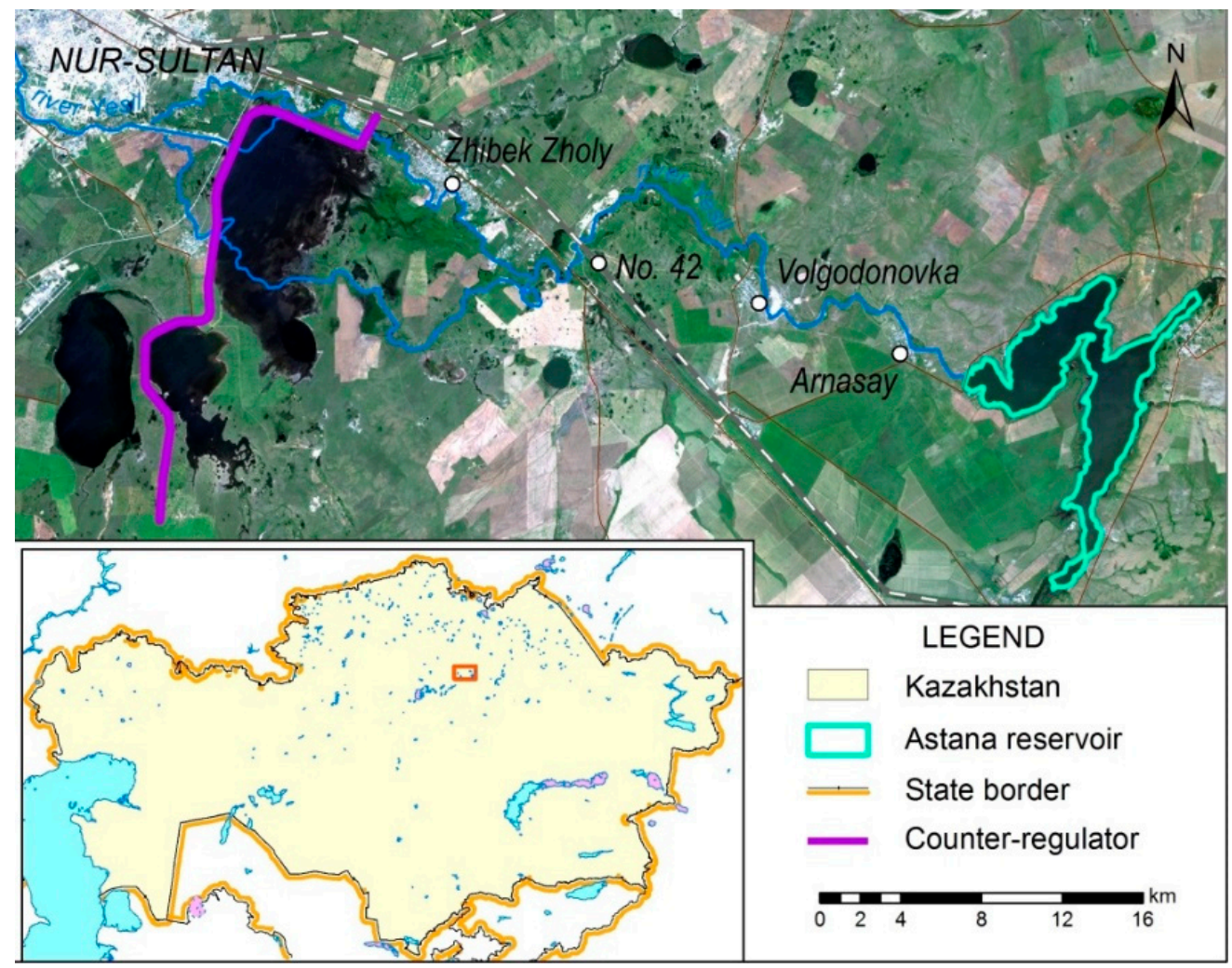

Figure 1. Location of the study area, hydraulic structures and settlements. 
The River Yesil (Ishim) is the main river in the study area. It originates in the Niyaz Mountains at an elevation of $561 \mathrm{~m}$ and flows into the Irtysh river. It is the only transboundary river which originates in Kazakhstan [26]. It has a watershed size of $177,000 \mathrm{~km}^{2}$, a total length of $2450 \mathrm{~km}$ and an average slope of $0.21 \%$. The study region covers approximately $56 \mathrm{~km}$ long section of the river. The long-term average annual flow at the Turgen station, which is located just above the Astana Reservoir, is $4.2 \mathrm{~m}^{3} / \mathrm{s}$ (1975-2018). The flow is characterized as heterogeneous within the hydrological year and over years [26]. As a result, the annual volume differences between years can reach $200-300 \%$. The analysis of the streamflow data indicates that the flow may be divided into three characteristic periods: (1) the highwater period from April to May (85-95\% of the total annual flow); (2) summer low water (June-October, 3-8\% of the flow); and (3) winter low flow (November-March, $0-3 \%$ ). Analysis of river-flow data for the last 25 years demonstrates that the start of spring highflow has shifted to an earlier period with an increase in overall volume, whereas the duration of the highflow period has halved [26]. In the study conducted by CAREC [25] on the influence of climate change on the hydrology of the upstream part of the River Yesil, the SWIM hydrological model was applied under two climate scenarios (Representative Concentration Pathways 2.5 and 8.5). The results indicate that, at the regional scale, the northern part of Central Asia, where our river is located, is expected to become wetter. Under both warming scenarios (moderate and strong) for 2041-2070, the monthly peak flow of the Yesil is expected to decrease, but it will occur over two months-March and April—as opposed to the current peak in April.

\subsection{Data Sources}

Hourly water-release data as well as the hydrographs for 10, 20 and 100-year flood events were obtained from the Republican State Enterprise Kazsushar. The data on the characteristics of the hydraulic structures was provided by the same organization. The opening of the reservoir's and regulator's gates followed the same actual operating rules. The land cover map for the whole study area was obtained from the Akimat of Tselinograd District. Roughness coefficient for each land cover type was assigned according to the HEC-RAS Hydraulic Reference Manual [27]. The Digital Elevation Model (DEM) is the most important input data for 2D models. In general, 2D hydraulic models are as good as the DEM used, because the correct topographical data influences the flood simulation results. Even though it constitutes the basic input data and governs the accuracy of the model, such data in high resolution is not freely available [28]. Commonly available SRTM and ASTER-GDEM datasets have a resolution of $30 \mathrm{~m}$, which for some locations may not be good enough. The importance of a correct DEM is pointed out by Kim et al. [9], who state that the uncertainties in topographic and hydrologic data are the main sources of uncertainty in flood predictions. It was therefore decided to improve the accuracy of available open-source DEM by several processing steps. The original available DEM was from Sentinel-1B, with a resolution of $10 \mathrm{~m}$. It was used as a base DEM, on which improvements were performed. A bathymetric survey of the riverbed, which comprised an area of 305.7 hectares, was conducted during the summer of 2019 using Sounder-Chartplotter Lowrance Elite 9 TI (Figure 2). In addition, aerial images of the river and floodplain were taken using quadrocopter DJI Phantom 4 (with Sony EXMoR $\frac{1}{2} \cdot 3^{\prime \prime}$ sensor and FOV 94o 20mm f/2.8 lense) over an area of 1696.3 hectares. The Sentinel-1B images were processed using ESA SNAP Desktop, whereas terrain data from the aerial images were processed in Agisoft PhotoScan Pro 4.2. As a result of processing, the resolution of the DEM in most of the study area ( $90.8 \%$ of the total study area) remained at $10 \mathrm{~m}$, while the areas with bathymetric survey of the river $(1.4 \%)$ and aerial photography of the floodplain $(7.8 \%)$ were improved to $2.5 \mathrm{~m}$. 


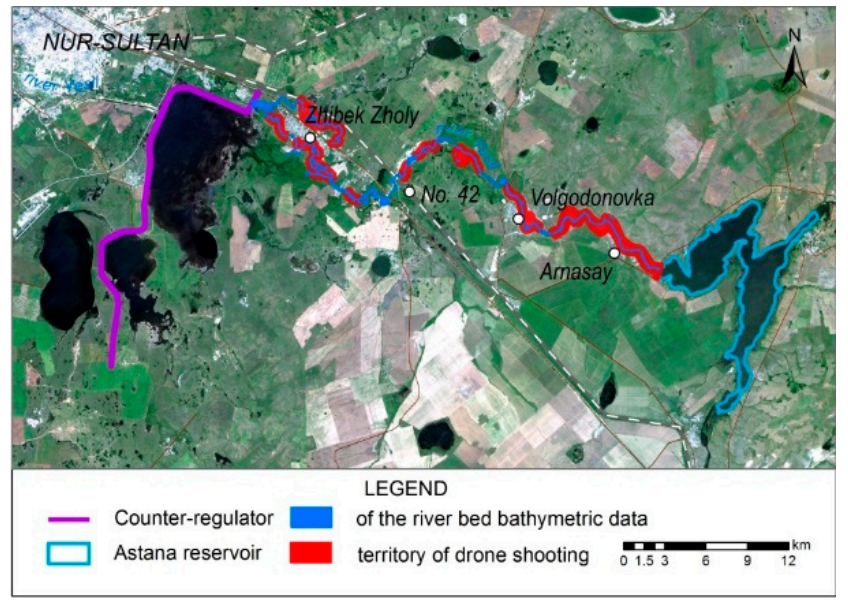

Figure 2. Territories with improved resolution of the DEM.

\subsection{Hydraulic Model}

As was mentioned earlier, the Hydrologic Engineering Center's River Analysis System (HEC-RAS 5.0.7) was used in this project. It is a free software developed by the US Army Corps of Engineers. HEC-RAS is widely used for performing 1D steady and unsteady flow, 2D unsteady flow river hydraulics calculations, sediment transport modelling, and water quality analysis [29].

HEC-RAS 2D uses shallow water equations, which describe the motion of water in terms of depth-averaged 2D velocity and water depth in response to the forces of gravity and friction. These equations represent the conservation of mass and momentum in a plane [1]. The finite-volume method used in HEC-RAS is described as advantageous, due to its conservativeness, geometric flexibility, and conceptual simplicity [1]. This solution approximates the average integral on a reference volume and allows a more general approach to unstructured mesh [4]. 2D modelling by HEC-RAS can simulate variability across and along the flow path. The model area is discretized into grid cells, where each cell uses the underlying terrain data with less loss in resolution (sub grid model). This results in the improvement of computational time [5]. For each cell and cell face HEC-RAS generates a detailed hydraulic property table (such as elevation-volume relationship, elevation-area, etc.) As a result, larger cells are produced, which can retain terrain details and use higher time steps. The water can move to any direction based on the given topography and the resistance to the flow controlled by the land use type and associated Manning's coefficient [2].

\subsection{Model Generation and Assessment}

In the first step, the sub-grid modelling capacity of HEC-RAS was evaluated for the study area. As Kim et al. [9] state, the main purpose of mesh design is to achieve the highest degree of accuracy for a given computational cost. While coarser resolution allows faster simulations at the expense of accuracy, smaller grid sizes can represent the terrain better, but will require a longer calculation time. For the purpose of assessment, three different grid sizes $(25,50$ and $75 \mathrm{~m})$ have been used to simulate the same event. This would allow the analysis of grid size influence on model results. In addition, the available papers on HEC-RAS 2D application $[2,6,16]$ do not consider the use of breaklines for mesh refinement. Thus, for the same grid size, two models were created: one with breaklines and another without. The breaklines included the high terrains present in the study area as well as river overbanks. The model performance by different grid sizes was evaluated using a high flow event from 2017 (Figure 3). This event was chosen as this was the only year for which hourly reservoir water release data and remote sensing images with clear skies were available. 


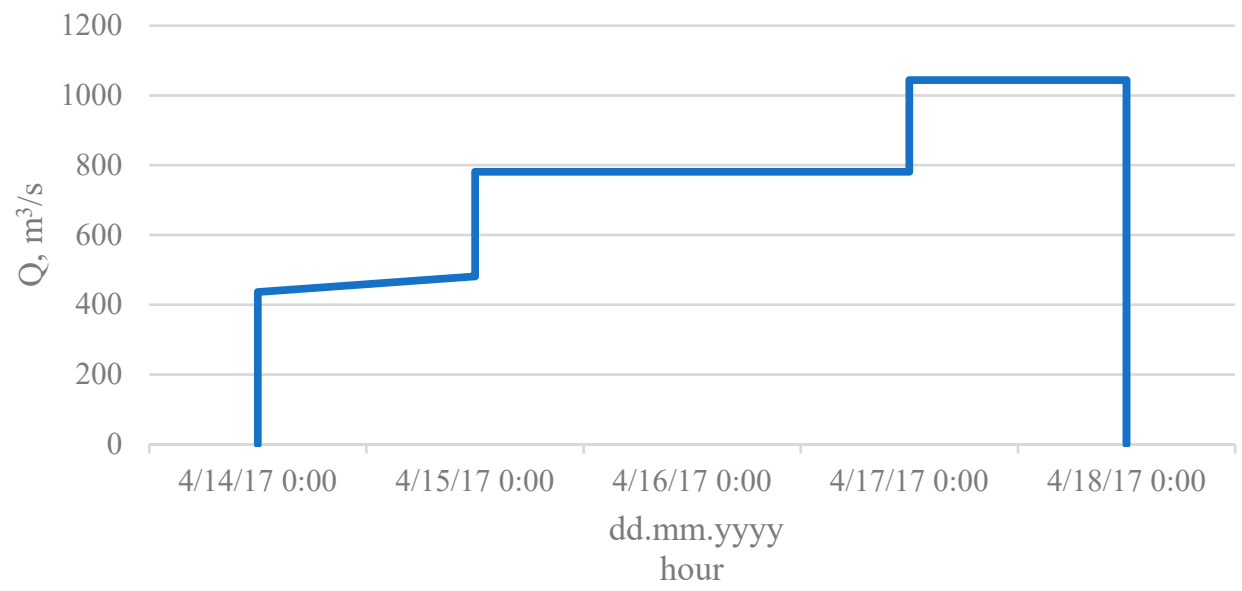

Figure 3. Hydrograph of water release from the Astana Reservoir during spring snowmelt in April 2017.

The total flow area comprised an area of 45,673 ha land. The release from the Astana Reservoir was used as an upstream boundary condition. Normal depth was used as the downstream boundary condition. In the model, water release from the Counter-Regulator for the event from 2017 was controlled by following the same gate-opening rules adopted by Kazsushar in 2017. In order to have a stable model, the time step was approximated using the Courant-Friedrichs-Lewy condition. Simulations were performed using the Diffusion Wave equation only, due to its higher stability and calculation speed. Trial simulations have shown that the use of a Full Momentum equation requires more than 21 times longer simulation time than the simulations using Diffusion Wave equation. As a result, for practical purposes (for conduction of sensitivity analysis and calibration), it was not considered viable. Evaluation of model results was performed using the Remote Sensing Image, which was obtained from the website planet.com. The satellite image of the flood extent on 19th April 2017 at 8:14:35 (UTC 00) was compared with the inundation boundary generated by HEC-RAS using the following Equations 1-4 from [28,30].

$$
\mathrm{F}=(\mathrm{A} /(\mathrm{A}+\mathrm{B}+\mathrm{C})) \times 100,
$$

Hit Rate $(\mathrm{H})=\mathrm{A} /$ Xobs,

False Alarm Ratio $($ FAR $)=($ Xsim $/$ Xobs $) /(\mathrm{A}+$ Xsim $/$ Xobs $)$,

$$
\text { Error Bias }(\mathrm{B})=(\mathrm{X} \operatorname{sim} / \text { Xobs }) /(\text { Xobs } / \text { Xsim }) \text {, }
$$

where A is the area correctly predicted as flooded (wet in both observed and simulated), B is the area overpredicting the extent (dry in observed, but wet in simulated) and $C$ is the underpredicted flood area (wet in observed, but dry in simulated) [6,28]. Even though Equation 1 is a common method for comparing binary maps, it has been described as being biased in favor of overpredicting the flood extent [28]. The Hit Rate, also called as the probability of detection, indicates how well the model replicates the observed data without penalizing for overprediction [30]. The False Alarm Ratio is an indicator of model overprediction [30]. Error bias between 0 and 1 indicates a tendency of the model to underpredict and a bias between 1 and infinity indicates a tendency of the model to overpredict [30].

After the initial assessment of different grid sizes, the selected grid size was further used to perform sensitivity analysis and the calibration of roughness coefficients. Afterwards, calibrated parameters were used for the simulation of floods of different return periods (10, 20 and 100). Flow hydrographs after the operation of Astana Reservoir during 10-, 20- and 100-year flood events was obtained from the Republican State Enterprise Kazsushar (Figure 4). 


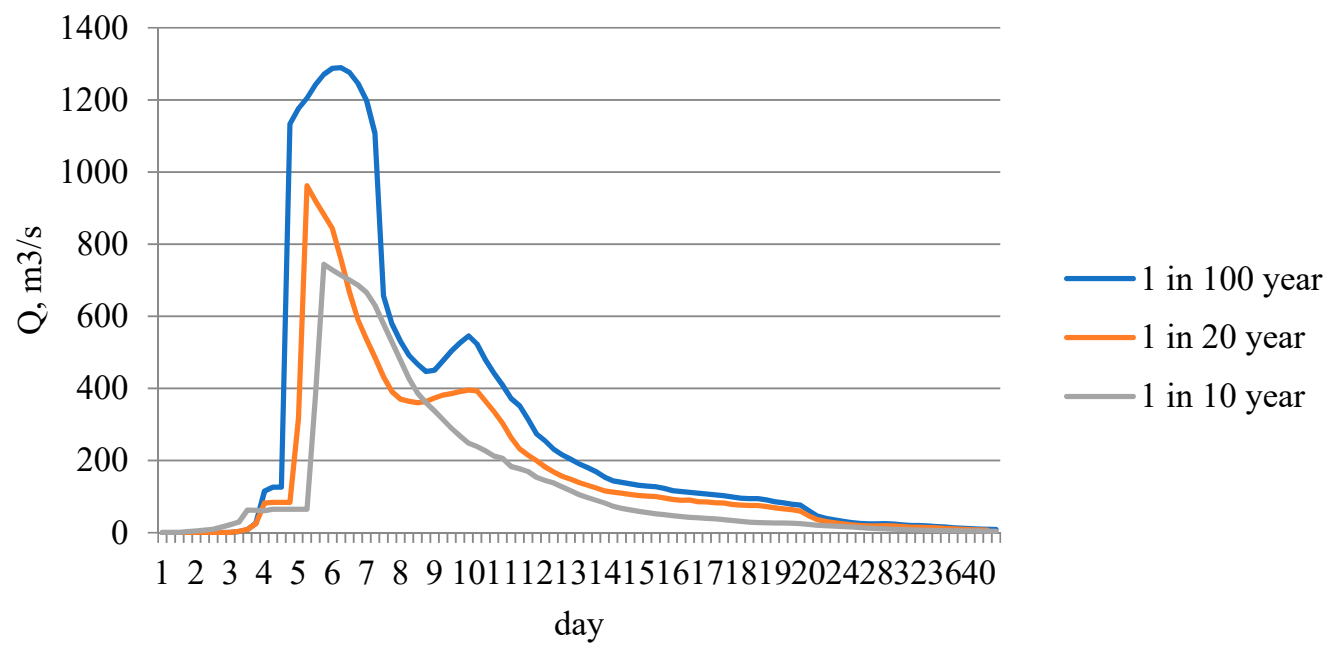

Figure 4. Hydrographs of water release from the Astana Reservoir during floods of 10-, 20- and 100-year return period.

The flood inundation areas generated were classified according to Flood Hazard classes (Classification 1) from MLIT [2]. This classification considers five classes, which are shown in Table 1.

Table 1. Flood hazard classification according to MLIT [2].

\begin{tabular}{ccc}
\hline Flood Hazard & Flood Depth $(\mathbf{m})$ & Hazard Classes \\
\hline H1 & $<0.5$ & Very low \\
H2 & $0.5-1$ & Low \\
H3 & $1-2$ & Medium \\
H4 & $2-5$ & High \\
H5 & $>5$ & Extreme \\
\hline
\end{tabular}

In addition to the classification from MLIT [2], more comprehensive flood hazard classification system (Classification 2) was developed for Kazakhstani conditions (Table 2). This system considers not only water depth, but also flow velocity as well as flood duration. The classification criteria were based on the natural characteristics of the study area and the impact of past flood events.

Table 2. Flood Hazard classification developed for Kazakhstani conditions

\begin{tabular}{cccc}
\hline Hazard Level & Flood Depth, $\mathbf{~}$ & Flow Velocity, $\mathbf{~} / \mathbf{s}$ & Flood Duration, Hours \\
\hline Low & up to 1 & up to 0.01 & up to 5 \\
Medium & $1-3$ & $0.01-0.05$ & $5-24$ \\
High & $3-5$ & $0.05-0.1$ & $24-72$ \\
Crisis & $5-7$ & $0.1-1.0$ & $72-120$ \\
Catastrophic & more than 7 & more than 1.0 & more than 120 \\
\hline
\end{tabular}

\section{Results}

\subsection{Performance of Different Grid Sizes}

The performances of different grid sizes in simulating the flood event from 2017 with and without breaklines are shown in Table 3. An additional row shows the results of the model with the octagonal mesh and breaklines. In comparison to the default rectangular mesh, the octagonal mesh allows water to flow in eight directions. As can be seen, the performance of the model did not vary significantly between different model versions with the initial Manning's values. The maximum coefficient $(58.7 \%)$ 
was obtained in the case of 75-m mesh without breaklines and the lowest performance $(57.9 \%)$ was observed for the $75-\mathrm{m}$ and $25-\mathrm{m}$ mesh with breaklines. The results indicate that the inclusion of breaklines did not significantly affect the model performance. Interestingly, the 75-m mesh model without breaklines showed a better performance than the same model with breaklines. There was no improvement in the case of the $25-\mathrm{m}$ mesh without breaklines.

Table 3. Model performance and simulation length at different grid size.

\begin{tabular}{cccccc}
\hline Model Version & $\begin{array}{c}\text { Model Performance, } \\
\text { F (\%) }\end{array}$ & H & FAR & B & $\begin{array}{c}\text { Simulation Length } \\
\text { (Minutes) }\end{array}$ \\
\hline 25-meter with breaklines & 57.9 & 0.77 & 0.00011 & 1.22 & 1064 \\
25-meter without breaklines & 58 & 0.77 & 0.00011 & 1.21 & 1271 \\
50-meter with breaklines & 58.4 & 0.79 & 0.00011 & 1.28 & 72 \\
50-meter without breaklines & 58.2 & 0.77 & 0.00011 & 1.21 & 106 \\
75-meter with breaklines & 57.9 & 0.77 & 0.00011 & 1.22 & 28 \\
75-meter without breaklines & 58.7 & 0.77 & 0.00011 & 1.17 & 23 \\
50-meter with breaklines & 58.1 & 0.77 & 0.00011 & 1.22 & 103 \\
\hline (octagonal mesh) & & & & &
\end{tabular}

In the case of the 50-m mesh, there was indeed a slight improvement in the model's performance. The octagonal mesh with a 50-m grid size demonstrated similar results to the 50-m mesh without breaklines. In terms of the Hit rate $(\mathrm{H})$, all the model versions showed similar values $(0.77)$, except for the 50-m mesh with breaklines (0.79). There was no variation among the model versions in terms of the False Alarm Ratio (FAR) value. Error bias (B) values demonstrate that all the model versions overpredict the flood extent. Interestingly, the highest overprediction was observed for 50-m mesh with breaklines, whereas the lowest overprediction was for 75-m without breaklines. Even though the mesh size did not have a significant influence on the model's performance, there was a significant difference in terms of simulation length. The longest time $(>17.5 \mathrm{~h})$ was observed for the $25-\mathrm{m}$ mesh, whereas the shortest time was for the 75-m mesh (23-28 $\mathrm{min}$ ). The 50-m mesh (both octagonal and rectangular) had a simulation time of 72-106 min. It is interesting to observe that even though the inclusion of breaklines did not significantly influence the model's performance, it did have an influence on the duration of the simulation. For the 25-m and 50-m meshes in particular, the inclusion of breaklines shortened the duration of the simulation. The reason for this could be the earlier leakage of water from the river cells to the floodplain cells in the case of the model without breaklines. This would consequently result in calculations at each time step taking place in more cells than for the case, where the leakage starts later due to the breaklines acting as barriers for flow. However, this was not the case for the 75-m mesh, where the opposite trend was observed.

Considering the model's performance for each mesh size, further simulations were done using the 50-m mesh model. This version was chosen for several reasons: (1) the simulation length was not as long as the 25-m mesh; (2) its version with breaklines performed better than the 75-m mesh with breaklines; and (3) it would consider more land-use types than 75-m mesh (depending on the study area). The last point is related to the structure of HEC-RAS 2D, which only allows one roughness coefficient per side. Specifically, during calculations it uses the land use type, which is located in the middle of the cell face.

\subsection{Sensitivity Analysis and Calibration}

Sensitivity analysis for land use types present in the study area was done using the 50-m mesh with breaklines. There were 33 land use types in total, 10 of which were found to be more sensitive than the others (Figure 5). 


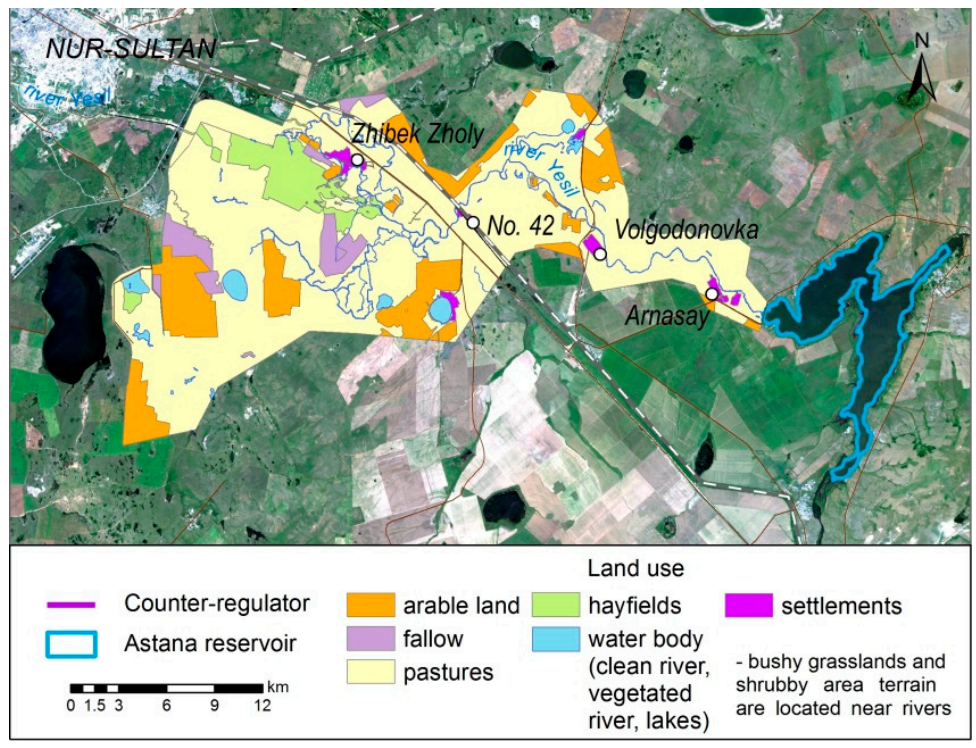

Figure 5. Map of the sensitive land use types present in the study area.

These land use types and their parameter ranges are shown in Table 4 in order of decreasing area. After the sensitivity analysis, manual calibration by trial and error was performed with these 10 land use types using the override regions function of HEC-RAS. In each simulation, only 1 roughness coefficient was modified and the rest were kept the same. Calibration by modifying all roughness coefficients at once (by giving different values to each one in every simulation) was not considered feasible due to the large number of possible combinations. The adopted method might not cover all the possible options (parameter combinations), but this is the only feasible option in the case of HEC-RAS with many roughness coefficients to calibrate. Calibration has increased the model performance in terms of the $\mathrm{F}$ statistic from $58.4 \%$ with initial parameters to $59.7 \%$ with calibrated parameters.

Table 4. Calibrated land use types and their parameter ranges.

\begin{tabular}{ccccc}
\hline Land Use Type & Area (ha) & Minimum & Maximum & Calibrated Value \\
\hline Pastures & 27,566 & 0.025 & 0.05 & 0.025 \\
Arable land & 7575.72 & 0.03 & 0.05 & 0.038 \\
Hayfields & 2478.8 & 0.02 & 0.04 & 0.055 \\
Bushy grasslands & 1072.1 & 0.035 & 0.07 & 0.035 \\
Fallow & 830.59 & 0.025 & 0.05 & 0.045 \\
Shrubby area & 790.92 & 0.045 & 0.11 & 0.048 \\
Settlements & 781.82 & 0.06 & 0.09 & 0.07 \\
Lakes & 702.58 & 0.03 & 0.05 & 0.04 \\
Clean river & 368.9 & 0.025 & 0.045 & 0.03 \\
Vegetated river & 36 & 0.045 & 0.065 & 0.045 \\
\hline
\end{tabular}

Figure 6 demonstrates the flood extent derived from the simulation using calibrated parameters. The correctly simulated areas are shown in blue, the areas underpredicted by the model are shown in yellow and the overpredicted areas are highlighted in red. It can be seen that there is a close agreement between the observed and simulated inundation areas, though certain areas are overestimated. The area upstream the Counter-Regulator is significantly overestimated. Considering the resolution of the satellite image and other potential errors in the input data (such as DEM accuracy), the simulation results were considered to be satisfactory. 


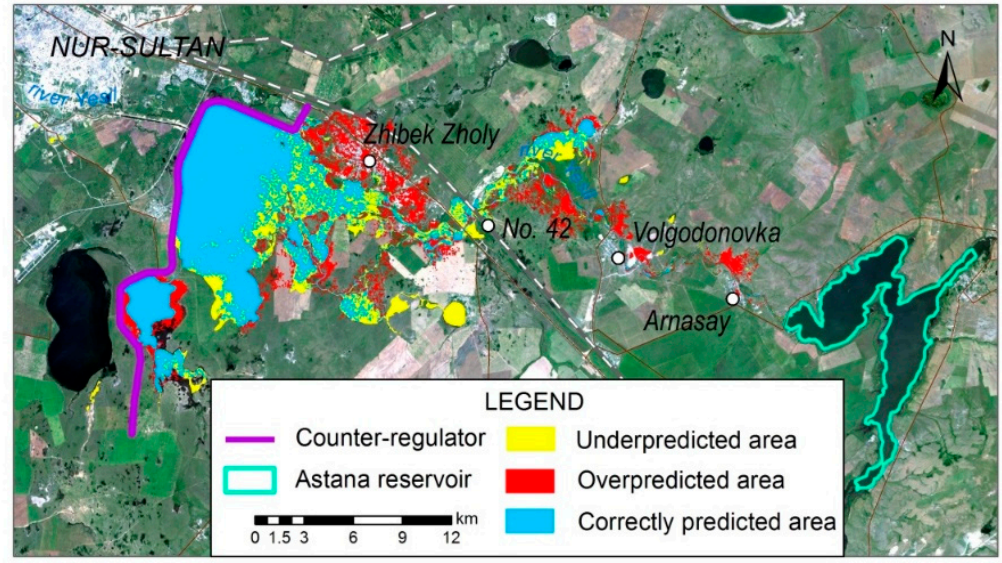

Figure 6. Inundation areas derived from satellite image and simulation by HEC-RAS (yellow-underpredicted area, red-overpredicted area, blue—correct prediction).

\subsection{Flood Inundation Mapping}

The calibrated roughness coefficients and the 50-m mesh with breaklines were used for flood inundation modelling. The maximum flows of the 10-, 20- and 100-year return period hydrographs corresponded to 744, 962 and $1289 \mathrm{~m}^{3} / \mathrm{s}$, respectively (Figure 4). Figures 7-9 illustrate the inundation maps after hazard classification according to MLIT. Table 5 shows the results of classification (MLIT) in terms of inundated area per hazard class for each scenario.

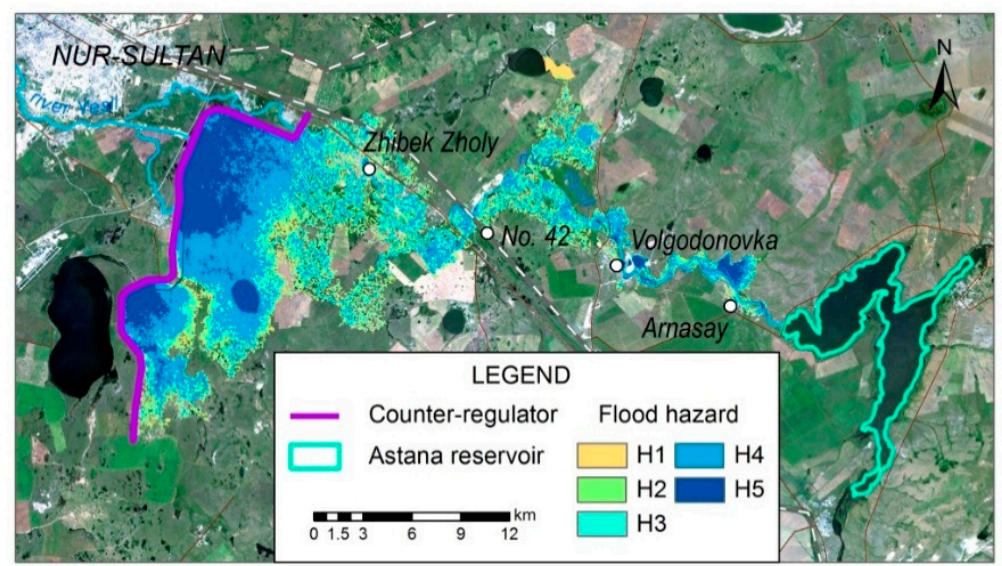

Figure 7. Hazard map (Classification 1) produced from the 100-year return period flow hydrograph.

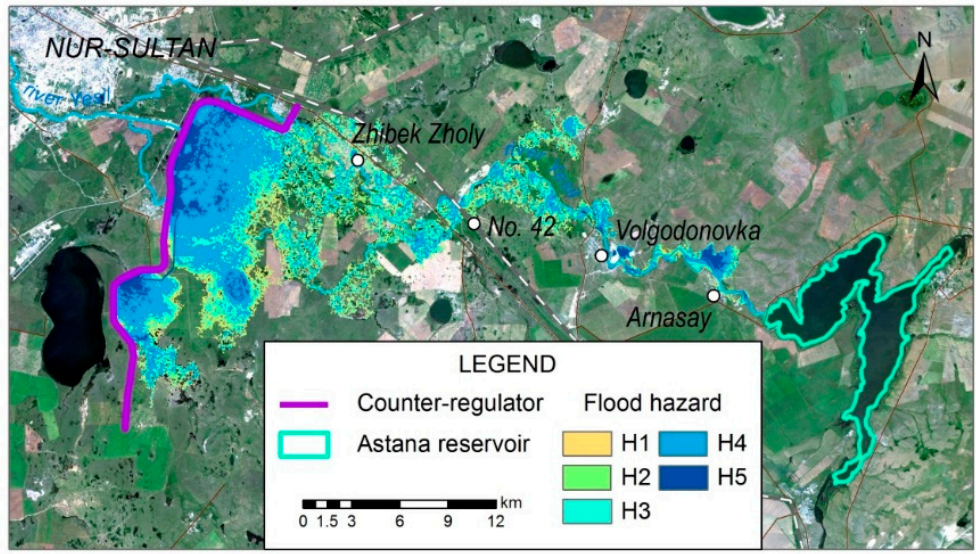

Figure 8. Hazard map (Classification 1) produced from the 20-year return period flow hydrograph. 


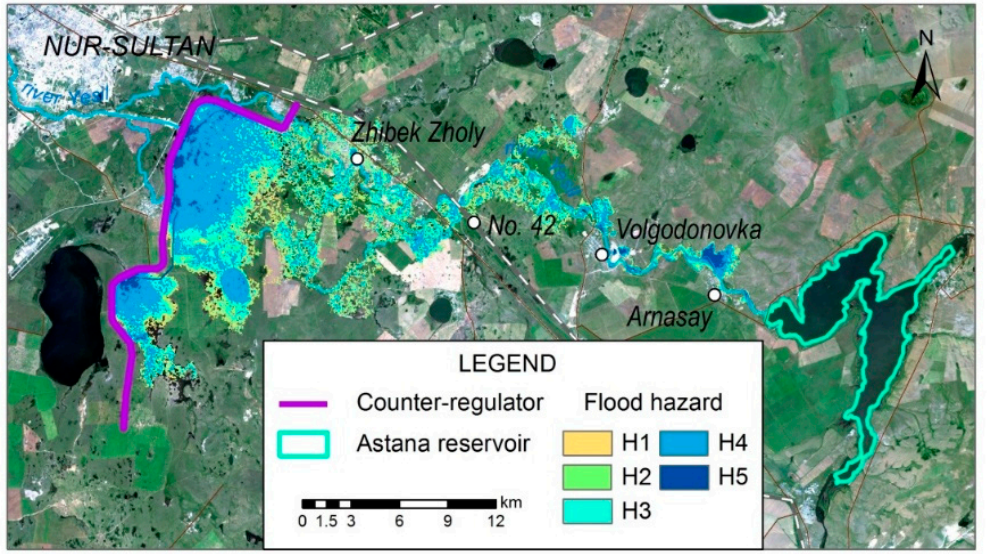

Figure 9. Hazard map (Classification 1) produced from the 10-year return period flow hydrograph.

Table 5. Results of flood hazard classification (Classification 1) for each scenario.

\begin{tabular}{ccccc}
\hline Hazard Classification & Water Depth & 100 Year (ha) & 20 Year (ha) & 10 Year (ha) \\
\hline H1 (very low) & $0-0.5 \mathrm{~m}$ & 2345.7 & 2192.54 & 2218.3 \\
H2 (low) & $0.5-1 \mathrm{~m}$ & 2331.8 & 2175.43 & 2159.64 \\
H3 (medium) & $1-2 \mathrm{~m}$ & 4284.8 & 3781.45 & 3903.53 \\
H4 (high) & $2-5 \mathrm{~m}$ & 8327.05 & 7259.43 & 6372.27 \\
H5 (extreme) & $>5 \mathrm{~m}$ & 4469.4 & 1666.72 & 852.83 \\
Total area (ha) & & $21,758.75$ & $17,075.57$ & $15,506.57$ \\
\hline
\end{tabular}

According to Table 5, the simulation of the 100-year flow hydrograph resulted in the largest area classified as being under extreme hazard. The same can be observed for the Medium and High Hazard classes. There was no significant difference in the size of the inundation area for very low and low hazard classes between the three events. The total inundation area shows a distinct trend towards decrease as the return periods of the flow hydrographs decrease. Such a classification identifies the areas which are prone to flooding and is a useful tool during the adoption of flood mitigation measures. Tables 5-7 show the areas of each settlement located in our study area which are classified to be under a particular hazard class according to Classification 1. The largest inundation is observed for Zhibek Zholy (Table 6), where the total inundated area increased from a 10 to a 100-year flood event. In all three scenarios, the largest inundated area was observed for the medium hazard class. The 100-year event resulted in 3.2 ha of land being affected by the flood with a depth of more than five meters; 172 ha of land had a water depth of around 1-2 m. In the case of settlement No. 42 (not shown), there was only very low hazard level in all three scenarios. The area under this hazard class was also small for all three scenarios $(<0.9 \mathrm{ha})$.

Table 6. Areas affected by the floods of different return periods for the settlement Zhibek Zholy (Classification 1).

\begin{tabular}{ccccc}
\hline Hazard Class & Water Depth & 10 Year (ha) & 20 Year (ha) & 100 Year (ha) \\
\hline H1 & $<0.5 \mathrm{~m}$ & 14.39 & 114.10 & 122.49 \\
H2 & $0.5-1 \mathrm{~m}$ & 12.64 & 104.40 & 106.90 \\
H3 & $1-2 \mathrm{~m}$ & 16.23 & 137.34 & 172.22 \\
H4 & $2-5 \mathrm{~m}$ & 9.40 & 83.23 & 124.80 \\
H5 & $>5 \mathrm{~m}$ & 0.24 & 2.23 & 3.21 \\
Total area (ha) & & 52.90 & 440.62 & 528.06 \\
\hline
\end{tabular}

In the village Volgodonovka $<1$ ha land was flooded overall by the 10- and 20-year flood events (Table 7). During the 100-year flood event, on the other hand, the total inundation area comprised 35.8 ha land and around 1.7 ha of that land was classified as being under high hazard and 8.3 ha 
as medium hazard. As can be seen from Table 8, the village of Arnasay is the second settlement to experience significant flooding in terms of the total area of inundation. The 100-year event resulted in 13.7 ha of land having a water depth of $2-5 \mathrm{~m}$, and 14.8 ha of the total settlement area was classified as medium hazard.

Table 7. Areas affected by the floods of different return periods for the settlement Volgodonovka (Classification 1).

\begin{tabular}{ccccc}
\hline Hazard Class & Water Depth & 10 Year (ha) & 20 Year (ha) & 100 Year (ha) \\
\hline H1 & $<0.5 \mathrm{~m}$ & 0.18 & 0.42 & 15.64 \\
$\mathrm{H} 2$ & $0.5-1 \mathrm{~m}$ & 0.10 & 0.14 & 10.17 \\
$\mathrm{H} 3$ & $1-2 \mathrm{~m}$ & 0.00 & 0.04 & 8.25 \\
$\mathrm{H} 4$ & $2-5 \mathrm{~m}$ & 0.00 & 0.00 & 1.73 \\
H5 & $>5 \mathrm{~m}$ & 0.00 & 0.00 & 0.00 \\
Total area & & 0.28 & 0.60 & 35.77 \\
\hline
\end{tabular}

Table 8. Areas affected by the floods of different return periods for the settlement Arnasay (Classification 1).

\begin{tabular}{ccccc}
\hline Hazard Class & Water Depth & 10 Year (ha) & 20 Year (ha) & 100 Year (ha) \\
\hline H1 & $<0.5 \mathrm{~m}$ & 4.37 & 11.85 & 15.59 \\
H2 & $0.5-1 \mathrm{~m}$ & 3.17 & 8.09 & 12.61 \\
H3 & $1-2 \mathrm{~m}$ & 3.21 & 8.31 & 14.79 \\
H4 & $2-5 \mathrm{~m}$ & 4.78 & 9.79 & 13.73 \\
H5 & $>5 \mathrm{~m}$ & 0.05 & 0.23 & 0.81 \\
Total area & & 15.58 & 38.25 & 57.52 \\
\hline
\end{tabular}

Hazard maps generated using the Classification 2 are illustrated in Figures 10-12. Whereas the corresponding Table 9 indicate the areas classified to be under a certain Hazard class for each scenario simulated. As the Classification 2 integrates several variables (such as water depth, flow velocity and flood duration) than the Classification 1, it is considered to be more useful. Table 9 indicates that when Classification 2 is used much larger area is under the highest hazard class. Among the hazard classes low and medium classes comprise significantly small area in comparison to other classes in all scenarios. The areas classified to be under medium and high classes were not significantly different between 3 scenarios. The area classified to have low hazard class was significantly large for 100 year flood event than for 10 and 20 year events. The classes crisis and catastrophic show an increasing trend in terms of area as the return period of the flooding events increases. Overall, this classification resulted in a significantly different flood hazard pattern than the Classification 1.

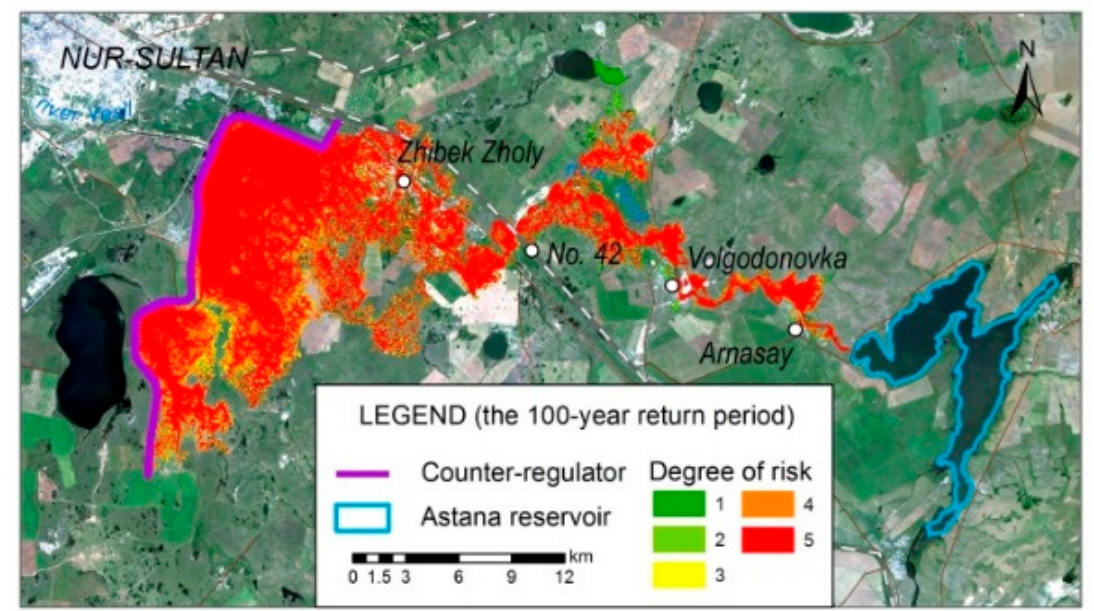

Figure 10. Hazard map (Classification 2) produced from the 100-year return period flow hydrograph. 


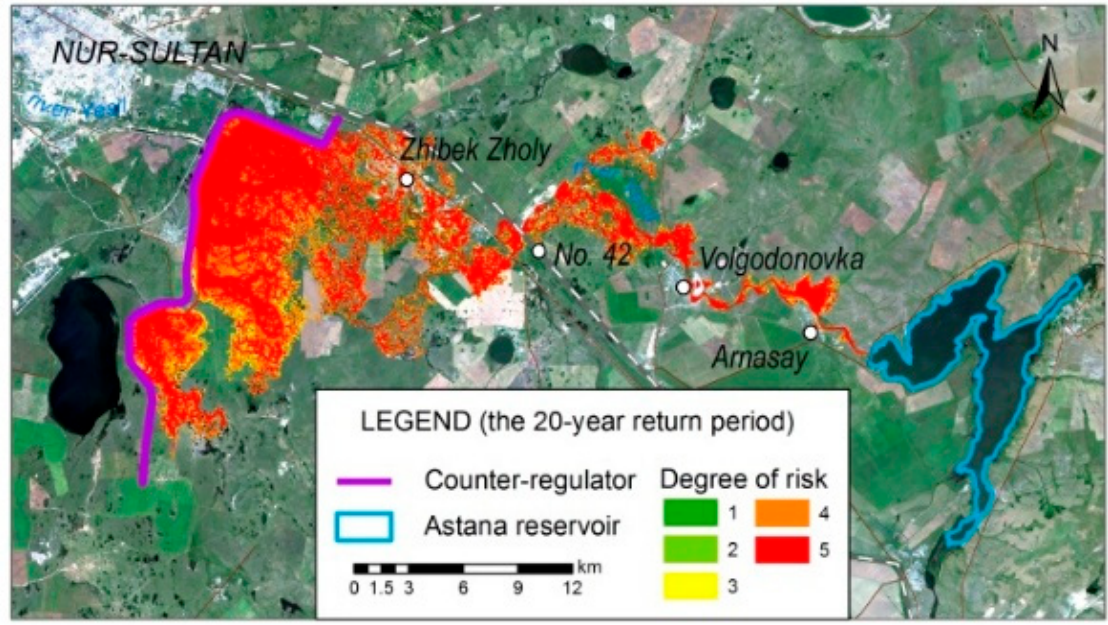

Figure 11. Hazard map (Classification 2) produced from the 20-year return period flow hydrograph.

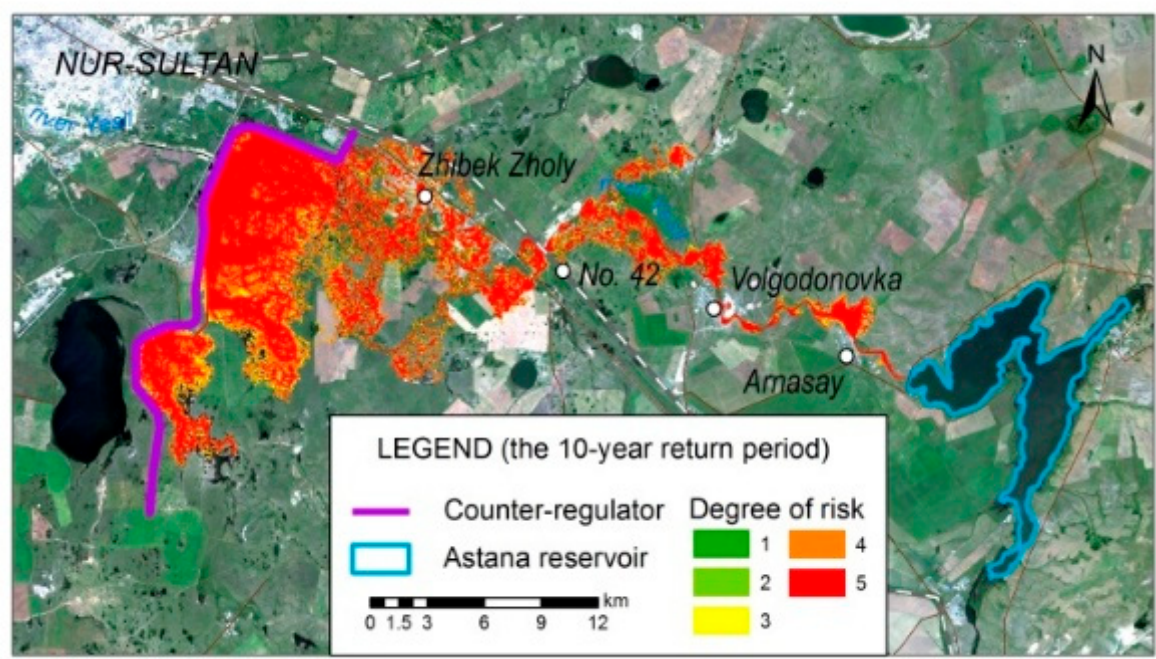

Figure 12. Hazard map (Classification 2) produced from the 10-year return period flow hydrograph.

Table 9. Results of flood hazard classification (Classification 2) for each scenario.

\begin{tabular}{cccc}
\hline \multirow{2}{*}{ Hazard Level } & \multicolumn{3}{c}{ Flood Hazard Classification, Hectares } \\
\cline { 2 - 4 } & 100-Year & 20-Year & 10 Year \\
\hline Low & 751.83 & 17.54 & 19.16 \\
Medium & 157.21 & 156.02 & 163.44 \\
High & 1316.05 & 1520.49 & 1520.5 \\
Crisis & 4886.73 & 4756.58 & 4405.25 \\
Catastrophic & $14,646.93$ & $10,624.94$ & 9398.22 \\
Total area & $21,758.75$ & $17,075.57$ & $15,506.57$ \\
\hline
\end{tabular}

In the Figures 13 and 14 the different Flood Hazard classes present in the settlements Arnasay and Zhibek Zholy are illustrated. Tables 10 and 11 show the areas in each settlement, which have different hazard levels. These settlements are located at different geomorphological positions and hydrological conditions. Village Arnasay is located on the right bank of the River Yesil within the high terrace above the floodplain. In all three scenarios, the floodplain area, where dry channels are present, experience the greatest inundation. The largest inundation area is observed for crisis and catastrophic classes in all scenarios. 100 year and 20 year events had similar area classified to be under 
high risk, whereas 10 year event had 3 times smaller area under this class. The low hazard class comprise significantly large area during 100 year event than during other 2 scenarios.
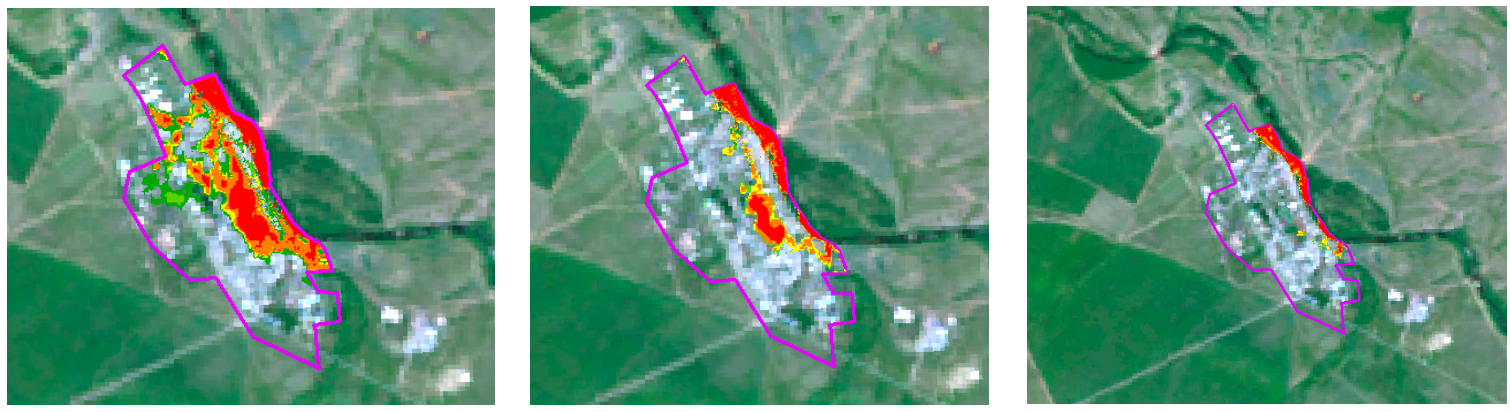

Figure 13. Flood hazard maps generated for the territory of the village Arnasay for different flood events. Left-100 year event, middle- 20 year flood event, right- 10 year flood event.
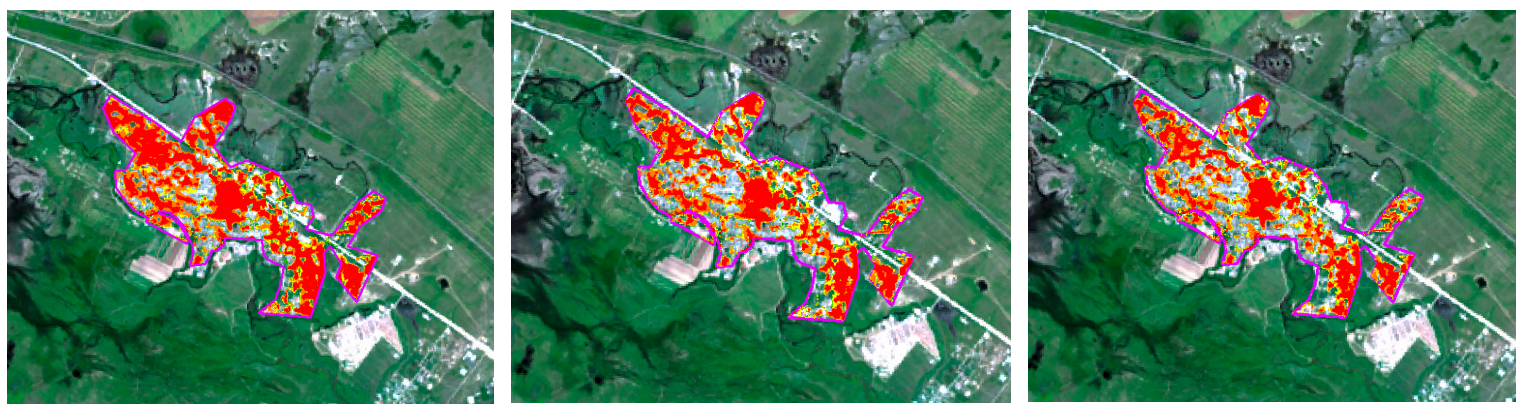

Figure 14. Flood hazard maps generated for the territory of the village Zhibek Zholy for different Figure 100. year event, middle- 20 year flood event, right- 10 year flood event.

Table 10. Areas affected by the floods of different return periods for the settlement Arnasay (Classification 2).

\begin{tabular}{cccc}
\hline \multirow{2}{*}{ RISK LEVEL } & \multicolumn{2}{c}{ Areas at Risk of Flooding of Various Levels, Hectares } \\
\cline { 2 - 4 } & 100-Year & 20-Year & 10 Year \\
\hline Low & 14.07 & 0.24 & 0.05 \\
Medium & 2.38 & 1.76 & 0.34 \\
High & 4.75 & 4.78 & 1.43 \\
Crisis & 18.13 & 6.67 & 2.5 \\
Catastrophic & 20.16 & 11.7 & 7.31 \\
Total area & 59.49 & 25.15 & 11.63 \\
\hline
\end{tabular}

Table 11. Areas affected by the floods of different return periods for the settlement Zhibek Zholy (Classification 2).

\begin{tabular}{cccc}
\hline \multirow{2}{*}{ Risk Level } & \multicolumn{2}{c}{ Areas at Risk of Flooding of Various Levels, Hectares } \\
\cline { 2 - 4 } & 100-Year & 20-Year & 10 Year \\
\hline Low & 14.72 & 2.53 & 2 \\
Medium & 6.08 & 15.34 & 13.25 \\
High & 56.82 & 65.12 & 66.67 \\
Crisis & 159.32 & 138.58 & 141.51 \\
Catastrophic & 298.91 & 211.62 & 186.91 \\
Total area & 535.85 & 433.19 & 410.34 \\
\hline
\end{tabular}


The village Zhibek Zholy is located within a low terrace between the reaches of the Yesil River after its bifurcation. As a result, there is higher risk of flooding in comparison to other settlements. During the 10 year return period flood event about $30-35 \%$ of the territory of the settlement is already subject to flooding (Figure 14). As in the case of Arnasay village, the largest inundation area was for crisis and catastrophic hazard classes. There was no significant difference in inundation extent for high hazard class. If 10 and 20 year events resulted in larger area under medium hazard class than the 100 year flood event, in terms of medium hazard class an opposite trend was observed. 10 and 20 year events resulted in similar flood inundation areas for all the classes, except catastrophic class. The obtained inundation maps and trends in inundation areas for each settlement could further be used for developing a number of protection measures from extreme events.

\section{Discussion}

Flooding events can cause significant economic loss and even human death. According to Dasallas et al. [5], they are considered to have the highest risk among hydro-meteorological hazards. It is therefore highly important to address these events in a way that reduces their negative influence on people and infrastructure. Flood simulation using hydraulic models is one of the main tools applied for that purpose. The current study is the pilot project on the application of HEC-RAS 2D for Kazakhstani conditions. The comparison of model performance by different grid sizes indicate no significant difference between the results. However, there is a significant difference in terms of simulation time between the different versions. Shustikova et al. [6] state that for large scale studies, 50-m (for LISFLOOD-FP) and 100-m resolutions (for HEC-RAS, with 1-m terrain) offer a compromise between accuracy and computational cost. According to our results, the 50-m mesh with breaklines was chosen as the optimum one. Even though the use of breaklines did not significantly influence the model's performance, their inclusion during the mesh generation is highly recommended. Barriers (indicated by breaklines) play an important role during flood propagation and our results show that their inclusion can shorten the simulation time. Jarihani et al. [24] pointed out that the mesh size in addition to DEM accuracy influences the calculation of the water inundation extent. As a result, this could be problematic, when the model results are compared with satellite images of the flood extent. Time savings due to larger mesh size is a key factor when the modeller is planning to perform calibration and uncertainty analysis. It is therefore important to perform the comparison of different grid sizes for any study area, in order to find the optimum mesh size. For the simulated event from 2017, hydrological processes such as infiltration and evaporation were considered to be negligible. Due to the frozen condition of the soil layer, it was safe to assume no infiltration in our case. Estimation of evapotranspiration from MOD16A2 and MYD16A2 demonstrated that during the simulation period (14-19 April 2017) an average ETP was around $6.4 \mathrm{~mm}$ for the study area. This is a much lower value than the simulated average water depth on 19 April $(1.94 \mathrm{~m})$ and so ETP loss was also assumed to be negligible.

Manual calibration of the roughness coefficients produced a slight improvement in the model's performance. The increase is not as significant as one would have expected, and the following could have been the reasons for that:

(1) DEM quality. If we consider the fact that the aerial images did not cover the whole river reach in the study area, these areas without improved DEM might have acted as a place for leakage of water. In such areas due to the resolution of the base DEM, there are no high terrains and the river floodplain is not clearly represented. As a result, when the water level rises, there are no barriers for water and with the low slope of the study area the water can travel a long distance and might result in a larger inundation area. The influence of high-resolution terrain data on model performance was demonstrated in the study by Shustikova et al. [6], where results increased when 1-m terrain data was used in comparison to coarser data. 
(2) HEC-RAS structure. There are cases of numerous dry as well as wet islands, which have been mentioned by Shustikova et al. [6] They have explained such islands to be the result of HEC-RAS sub grid configuration's struggle to produce a continuous inundation pattern. HEC-RAS does not require the first grid to be filled with water before flowing into the second grid. As a result, unless there is a barrier along the cell face, water can travel a long distance. It has been pointed out that this may be a limitation in the calculation of flood extent and the distribution of local water depth values [6]. In the current model, all the locations (where observable) where high terrains exist have been identified and included during the mesh generation.

(3) Snow cover. As was mentioned earlier, high flow events in the Yesil occur during the snowmelt season. The snowmelt water, which already exists in the flow area, may be collected resulting in inundation of certain low-lying areas. However, the existing snow cover in the study area was not considered during the simulations due to the absence of snow cover data and the inability to consider snowmelt processes in HEC-RAS.

Considering this insignificant increase in the model's performance after calibration, it is possible that a significant increase would not be obtained if the calibration was performed with the 25- and 75-m model versions. Regarding this, Shustikova et al. [6] mention that the difference between the calibrated parameters' values from different mesh sizes was less than $1 \%$. The calibrated model demonstrated plausible results in terms of the inundation extent and was used for flood inundation modelling using 10-, 20- and 100-year flow hydrographs. It should be clarified that these simulated hydrographs consider the operation of Astana Reservoir during 10-, 20- and 100-year flood events. As a result, they represent the water release from the hypothetical reservoir operation. However, looking at the simulated inundation maps, we can already observe the major territories, which are prone to flooding. These are the areas where there is water in all three scenarios. Information about these areas could be used for long-term land use planning, for the generation of adequate development plans and for the evaluation of costs for flood reduction measures by local authorities $[9,10]$. Nevertheless, it is stated that the following three factors contribute to the accuracy of flood modelling: (1) structural model errors; (2) input data errors; and (3) numerical errors [9]. Decision makers should therefore have a certain level of awareness about these factors while using the modelling results. The hazard classification for each settlement indicates that Zhibek Zholy is the most impacted location in all three scenarios. This is also observed, as it is periodically flooded during the spring snowmelt. The local authorities should consider measures (structural and non-structural) to reduce the flood risk by assessing their socio-economic, as well as their environmental consequences, perhaps using hydraulic modelling. One of the major considerations for this modelling project was to assess if the Counter-Regulator, the main function of which is to protect the capital city from flood water and extreme releases from the Astana Reservoir, can hold the water volume from the 100-year flood event. When this event was simulated, the maximum water surface elevation at the Counter-Regulator was lower than the dam crest by approximately two meters and we can therefore assume that during such an event with the assumed operation of the gates overflow of the dam is not expected.

There are several potential research directions which can be mentioned as the next step. Comparison of HEC-RAS results with other 2D models such as Iber and BASEMENT would be of interest. All three models are free and such a comparison will highlight the advantages and disadvantages of each model's structure as well as the assumptions for the applied location. Due to the importance of the capital city and neighboring settlements, the assessment of structural measures (levees, diversion channels, etc.) for flood risk mitigation purposes during high-water releases from the hydraulic structures is another topic which needs consideration. The absence of high-resolution terrain data (such as LiDAR) restricted the scope of this project. Finally, conduction of probabilistic dam break simulations has an immense importance for emergency preparation actions and ideally such studies should be conducted for all the important reservoirs present in the country. 


\section{Conclusions}

The hydrodynamic model HEC-RAS 2D and improved DEM (with the inclusion of river bathymetry and terrain data from the aerial images) were used for the simulation of high flow releases from the Astana Reservoir. Comparison of different mesh sizes (25, 50 and $75 \mathrm{~m})$ for the simulation of the event from 2017 demonstrated no significant difference in terms of model performance between different model versions. However, substantial differences in simulation time have been observed. In addition, the inclusion of breaklines, though it did not result in consistent performance improvement, demonstrated the shortening of simulation duration. Sensitivity analysis and subsequent manual calibration resulted in a slight improvement in the performance of the model. The following were considered to be the main reasons for such outcomes: DEM quality, HEC-RAS structure and the influence of snowmelt processes. Overall, the model demonstrated plausible results and the extent of the flood modelled corresponded well to the flood extent from the satellite image. The flood inundation maps from the simulation of 10-, 20- and 100-year hydrographs have been classified according to the hazard classes. The hazard maps indicated the locations that are prone to flooding in the three scenarios. Construction of any buildings should be prohibited at these locations. The inundation areas identified in the settlements should be used by the local authorities for the adoption of structural and non-structural measures depending on the hazard class assigned.

Author Contributions: Conceptualization, N.O. and F.A.; methodology, N.O., F.A., Y.K., A.M. and N.Z.; software, N.O. and Y.K.; validation, N.O., Y.K. and A.M.; formal analysis, N.O., F.A., A.M. and N.Z.; resources, N.O.; data curation, F.A., Y.K., A.M. and N.Z.; writing — original draft preparation, N.O.; writing-review and editing, N.O., F.A., Y.K. and A.M.; visualization, N.O., F.A., Y.K. and N.Z.; project administration, F.A.; funding acquisition, F.A. All authors have read and agreed to the published version of the manuscript.

Funding: This research was funded by The Committee of Science of The Ministry of Education and Science of The Republic of Kazakhstan, within the framework of the project AP05136087 "Hydrological computer modelling of the Yesil and Nura Rivers flooding to identify the Astana city area and surrounding settlements inundation risk".

Conflicts of Interest: The authors declare no conflict of interest. The funders had no role in the design of the study; in the collection, analyses, or interpretation of data; in the writing of the manuscript, or in the decision to publish the results.

\section{References}

1. Teng, J.; Jakeman, A.J.; Vaze, J.; Croke, B.F.W.; Dutta, D.; Kim, S. Flood inundation modelling: A review of methods, recent advances and uncertainty analysis. Environ. Model. Softw. 2017, 90, 201-216. [CrossRef]

2. Mihu-Pintilie, A.; Cîmpianu, C.I.; Stoleriu, C.C.; Pérez, M.N.; Paveluc, L.E. Using high-density LiDAR data and 2D streamflow hydraulic modeling to improve urban flood hazard maps: A hec-ras multi-scenario approach. Water 2019, 11, 1832. [CrossRef]

3. Burlibayev, M.; Volchek, A.; Kalinin, M. Hydrological natural phenomena (world trends, chronicle of Belarus and Kazakhstan). In Proceedings of the Water Resources of Central Asia and Their Use, Aktobe, Kazakhstan, 22-23 September 2016; Volume 2, pp. 372-377.

4. Patel, D.P.; Ramirez, J.A.; Srivastava, P.K.; Bray, M.; Han, D. Assessment of flood inundation mapping of Surat city by coupled 1D/2D hydrodynamic modeling: A case application of the new HEC-RAS 5. Nat. Hazards 2017, 89, 93-130. [CrossRef]

5. Dasallas, L.; Kim, Y.; An, H. Case study of HEC-RAS 1D-2D coupling simulation: 2002 Baeksan flood event in Korea. Water 2019, 11, 2048. [CrossRef]

6. Shustikova, I.; Domeneghetti, A.; Neal, J.C.; Bates, P.; Castellarin, A. Comparing 2D capabilities of HEC-RAS and LISFLOOD-FP on complex topography. Hydrol. Sci. J. 2019, 64, 1769-1782. [CrossRef]

7. Ramirez, J.A.; Rajasekar, U.; Patel, D.P.; Coulthard, T.J.; Keiler, M. Flood modeling can make a difference: Disaster risk-reduction and resilience-building in urban areas. Hydrol. Earth Syst. Sci. Discuss. 2016. [CrossRef]

8. Wright, N.G.; Crosato, A. The hydrodynamics and morphodynamics of rivers. In Treatise on Water Science; Four-Volume Set; Wilderer, P.A., Ed.; Elsevier: Oxford, UK, 2011; Volume 2, pp. 135-156. ISBN 978-0-444-53199-5. 
9. Kim, B.; Sanders, B.F.; Schubert, J.E.; Famiglietti, J.S. Mesh type tradeoffs in 2D hydrodynamic modeling of flooding with a Godunov-based flow solver. Adv. Water Resour. 2014, 68, 42-61. [CrossRef]

10. Asselman, N.; Bates, P.; Fewtrell, T.; Soares-Frazão, S.; Zech, Y.; Velickovic, M.; de Wit, A.; ter Maat, J.; Verhoeven, G. Flood Inundation Modelling Executive Summary. 2009. Available online: https://ecapra.org/ sites/default/files/documents/Flood\%20Inundation\%20Modelling.pdf (accessed on 10 May 2020).

11. Thakur, B.; Parajuli, R.; Kalra, A.; Ahmad, S.; Gupta, R. Coupling HEC-RAS and HEC-HMS in precipitation runoff modelling and evaluating flood plain inundation map. In Proceedings of the World Environmental and Water Resources Congress 2017, Sacramento, CA, USA, 21-25 May 2017; pp. 240-251. [CrossRef]

12. Fassoni-Andrade, A.C.; Fan, F.M.; Collischonn, W.; Fassoni, A.C.; Paiva, R.C.D. Comparison of numerical schemes of river flood routing with an inertial approximation of the Saint Venant equations. RBRH 2018, 23. [CrossRef]

13. Morsy, M.M.; Goodall, J.L.; O’Neil, G.L.; Sadler, J.M.; Voce, D.; Hassan, G.; Huxley, C. A cloud-based flood warning system for forecasting impacts to transportation infrastructure systems. Environ. Model. Softw. 2018, 107, 231-244. [CrossRef]

14. Costabile, P.; Macchione, F.; Natale, L.; Petaccia, G. Flood mapping using LIDAR DEM. Limitations of the 1-D modeling highlighted by the 2-D approach. Nat. Hazards 2015, 77, 181-204. [CrossRef]

15. Loi, N.K.; Liem, N.D.; Tu, L.H.; Hong, N.T.; Truong, C.D.; Tram, V.N.Q.; Nhat, T.T.; Anh, T.N.; Jeong, J. Automated procedure of real-time flood forecasting in $\mathrm{Vu} \mathrm{Gia}-\mathrm{Thu}$ Bon river basin, Vietnam by integrating SWAT and HEC-RAS models. J. Water Clim. Chang. 2019, 10, 535-545. [CrossRef]

16. Quiroga, V.M.; Kurea, S.; Udoa, K.; Manoa, A. Application of 2D numerical simulation for the analysis of the February 2014 Bolivian Amazonia flood: Application of the new HEC-RAS version 5. Ribagua 2016, 3, $25-33$. [CrossRef]

17. Vozinaki, A.-E.K.; Morianou, G.G.; Alexakis, D.D.; Tsanis, I.K. Comparing 1D and combined 1D/2D hydraulic simulations using high-resolution topographic data: A case study of the Koiliaris basin, Greece. Hydrol. Sci. J. 2017, 62, 642-656. [CrossRef]

18. Salt, D.V. A Comparison of HEC-RAS and DSS-WISE Lite 2D Hydraulic Models for a Rancho Cielito Dam Breach; California State University: Sacramento, CA, USA, 2019.

19. Brunner, G. Benchmarking of the HEC-RAS Two-Dimensional Hydraulic Modeling Capabilities; U.S. Army Corps of Engineers: Davis, CA, USA, 2018; pp. 1-137.

20. Rangari, V.A.; Umamahesh, N.V.; Bhatt, C.M. Assessment of inundation risk in urban floods using HEC RAS 2D. Model. Earth Syst. Environ. 2019, 5, 1839-1851. [CrossRef]

21. Kumar, N.; Kumar, M.; Sherring, A.; Suryavanshi, S.; Ahmad, A.; Lal, D. Applicability of HEC-RAS 2D and GFMS for flood extent mapping: A case study of Sangam area, Prayagraj, India. Model. Earth Syst. Environ. 2020, 6, 397-405. [CrossRef]

22. Costabile, P.; Costanzo, C.; Ferraro, D.; Macchione, F.; Petaccia, G. Performances of the new HEC-RAS version 5 for 2-D hydrodynamic-based rainfall-runoff simulations at basin scale: Comparison with a state-of-the art model. Water 2020, 12, 2326. [CrossRef]

23. Pilotti, M.; Milanesi, L.; Bacchi, V.; Tomirotti, M.; Maranzoni, A. Dam-Break Wave propagation in alpine valley with HEC-RAS 2D: Experimental cancano test case. J. Hydraul. Eng. 2020, 146, 05020003. [CrossRef]

24. Akiyanova, F.; Frolova, N.; Karakulov, E.; Kezhebayeva, A.; Shaimerdenova, A. Materials and methods of floods risk assesment on the Esil and Nura rivers within Astana suburban area. Hydrometeorol. Ecol. 2018, 3, 95-109.

25. CAREC Climate Change and Hydrology in Central Asia: A Survey of Selected Basins. Available online: https://www. dropbox.com/s/t3tefbrwmqxju14/Climate-Hydrology-CA-Final-WEB_\%20pdf\%20eng.pdf?dl=0 (accessed on 22 August 2020).

26. Akiyanova, F.Z.; Frolova, N.L.; Avezova, A.A.; Shaimerdenova, A.M.; Oleshko, A.B. Water resources and system of the River Yesil (ISHIM) under conditions of active anthropogenous transformation and climate change. Eurasian J. Biosci. 2019, 13, 1275-1289.

27. Brunner, G. HEC-RAS River Analysis System: Hydraulic Reference Manual, Version 5.0.; US Army Corps of Engineers Hydrologic Engineering Center (HEC): Davis, CA, USA, 2016; pp. 1-538.

28. Jarihani, A.A.; Callow, J.N.; McVicar, T.R.; Van Niel, T.G.; Larsen, J.R. Satellite-derived Digital Elevation Model (DEM) selection, preparation and correction for hydrodynamic modelling in large, low-gradient and data-sparse catchments. J. Hydrol. 2015, 524, 489-506. [CrossRef] 
29. Leon, A.S.; Goodell, C. Controlling HEC-RAS using MATLAB. Environ. Model. Softw. 2016, 84, 339-348. [CrossRef]

30. Sampson, C.C.; Smith, A.M.; Bates, P.D.; Neal, J.C.; Alfieri, L.; Freer, J.E. A high-resolution global flood hazard model. Water Resour. Res. 2015, 51, 7358-7381. [CrossRef] [PubMed]

(C) 2020 by the authors. Licensee MDPI, Basel, Switzerland. This article is an open access article distributed under the terms and conditions of the Creative Commons Attribution (CC BY) license (http://creativecommons.org/licenses/by/4.0/). 